\section{Letter to the Editor}

\section{"Corresponding author}

Hala Mourad Demerdash, PhD

Associate Professor

Department of Clinical Chemistry and Hematology

Pharos University in Alexandria

Al Shri Al Omomi, Qism Sidi Gabir

Alexandria Governorate, Egypt

E-mail: demerdashh@yahoo.com

Volume 2 : Issue 3

Article Ref. \#: 10000ROJ2115

\section{Article History}

Received: October $26^{\text {th }}, 2015$

Accepted: October $28^{\text {th }}, 2015$

Published: October $28^{\text {th }}, 2015$

\section{Citation}

Demerdash HM. Obesity and trace elements. Obes Res Open J. 2015 2(3): 98-100. doi: 10.17140/OROJ $2-115$

\section{Copyright}

(C2015 Demerdash HM. This is an open access article distributed under the Creative Commons Attribution 4.0 International License (CC BY 4.0), which permits unrestricted use, distribution, and reproduction in any medium, provided the original work is properly cited.

\title{
Obesity and Trace Elements
}

Hala Mourad Demerdash ${ }^{\star}$

Department of Clinical Chemistry and Hematology, Pharos University in Alexandria, Al Shri Al Omomi, Qism Sidi Gabir, Alexandria Governorate, Egypt

Obesity has been identified as a medical problem. Obesity may be associated with abnormal metabolism and micronutrient deficiencies. Thus, obesity and malnutrition at the same time is a reality. However, in the past it was unusual to say that people who eat much were liable to be malnourished. Now-a-days, eating too much does not mean meeting nutritional requirements. This is due to the fact that several factors affect those requirements; as nature of diet, dietary habits, food preparation and host-related factors as intestinal absorption.

Trace elements are of great value in regulation of normal body metabolism, as they interact with many enzymes and hormones; some of which will be discussed.

\section{MAGNESIUM}

It is the second most abundant intracellular cation, approximately $50 \%$ of total body magnesium is found in bones. The other $50 \%$ is found inside cells of body tissues and only $1 \%$ is found in blood. Magnesium is essential for absorption and utilization of nutrients; carbohydrates, fats and proteins. It is a critical cofactor for hundreds of enzymes especially those involved in glucose metabolism and a direct antagonist of intracellular calcium. Moreover, it is associated with insulin sensitivity. As hypomagnesaemia results in reduced insulin sensitivity of peripheral tissue through reduced auto-phosphorylation of tyrosine kinase, a component of the $\beta$-subunit of the insulin receptor for which magnesium is a co-factor. Also, hypomagnesaemia may be associated with reduced $\beta$-cells proliferation and thus affecting insulin production. Therefore, serum magnesium levels are negatively correlated with Insulin Resistance (HOMAIR).

The exact mechanism of hypomagnesaemia in obese patients is unclear but may be related to eating habits; as increased intake of carbonated soft drinks, which are rich in phosphorous and thereby interfere with magnesium absorption, or increased intake of caffeine resulting in increased magnesium excretion. Another mechanism may be increased intake of dairy products with high $\mathrm{Ca}+$ content and or fat content thus interfere with its absorption. ${ }^{1}$

\section{IRON}

Iron is essential co-factor; it is a constituent of a number of important macromolecules, including those involved in energy production, Deoxyribonucleic acid (DNA) synthesis and metabolism. On the other hand, iron can be dangerous being a catalyst of free radical reactions. Because of this dual nature, iron balance is tightly regulated. Most of iron in body is incorporated to heme biosynthesis in erythropoietic bone marrow and other heme containing enzymes, the remaining amount is found in hepatocytes and cells of reticuloendothelial system.

Obesity may promote iron deficiency through inhibition of dietary iron absorption from the duodenum. Under normal conditions, iron absorption is dependent on both a divalent metal transporter and the iron exporter Ferroportin (FPN). FPN is regulated by hepcidin. The liver derived peptide hormone hepcidin is the primary regulator of iron hemostasis; which is both an inhibitor of intestinal iron absorption as well as macrophage iron release. In the 
intestines hepcidin exerts its effect by binding to iron exporter ferroportin (FPN) leading to FPN phosphorylation, degradation and decreased iron absorption. Also pro-inflammatory cytokines secreted from adipose tissue in obese subjects stimulate hepcidin release from adipose tissue. In addition, these cytokines as Interleukin 1 (IL-1) and Interleukin 6 (IL-6) may interfere with erythropoietin hormone secretion, and blunt the erythroid precursor response to the hormone. ${ }^{2}$

Moreover, lipocalin 2, an iron binding protein is produced by adipose tissue and could lead to sequestration of iron stores making them unavailable for hemoglobin or myoglobin formation. Over-secretion of these proteins (hepcidin and lipocalin 2) leads to increased iron content in adipose tissue, thus preconditions for adverse effects of local iron overload; as iron is capable of inducing oxidative stress, inflammation and adipose tissue endocrine dysfunction. Thus, obesity is associated with both elevated body iron stores and iron deficiency. Resultant iron deficiency and anemia may impair mitochondrial and cellular energy homeostasis and further increase fatigue of obese subjects. $^{2}$

\section{ZINC}

It is an important element in DNA synthesis, gene expression and activity of various enzymes and maintenance of normal growth. It plays a critical role in integrity of the immune system and wound healing. It is also found to enhance synthesis, storage and release of insulin. Zinc deficiency has been reported in obese subjects. However, the exact mechanism is unclear. It may be due to Zinc accumulation in the adipose tissue, as result of increased production of adipokines, increased Leptin production. They induce chronic inflammation and expression of metallothioein and Zinc-Copper transporter in hepatocytes. These proteins result in accumulation of these metals in hepatocytes and adipose tissue and decreased serum concentration. ${ }^{3}$ Decreased serum Zinc concentration in obese patients plays a role in insulin resistance.

\section{COPPER}

Most of absorbed dietary copper is transported to hepatocytes, which utilize it for their metabolism as respiration due to its role in cytochrome oxidase function at the mitochondrial electron transport chain and free-radical defense being antioxidant. Serum Copper levels were reported to be significantly higher in obese patients compared to normal body weight controls. Some authors reported a negative correlation between serum Copper and High-density lipoprotein (HDL)-cholesterol. ${ }^{4}$

The mechanism for its elevation in obese patients is unclear but it is thought to be due to pro-inflammatory cytokines released from adipose tissue as IL-1 enhance intra-cellular Zinc accumulation with intra-cellular Copper efflux, and when released to blood it binds to Ceruloplasmin. High serum copper and low serum zinc were associated with increased cardiovascular mortality. ${ }^{5}$

Copper imbalance often results in a reduced desire for protein, especially animal protein. Also high tissue copper aggravates obesity. It is always associated with high serum leptin. In addition, its excess tends to raise tissue sodium levels while lowering tissue potassium levels. High sodium level subsequently results in water retention. Low potassium results in hypoglycemia and sweet cravings. ${ }^{6}$

\section{CHROMIUM}

Chromium is considered an essential ultra-trace metal. Once absorbed from intestines, it is distributed to various organs of the body, especially the kidney, muscle, and liver. The principal carrier protein is transferrin, which plays a critical role in the movement of chromium from blood to Low-molecular-weight chromium (LMWCr); oligopeptide low-molecular weight (LMW) chromium (LMWCr)-binding substance (MW $\sim 1,500 \mathrm{Da})$. Thereby amplifies the intracellular insulin signal. Therefore, chromium is an active factor in the substance; Glucose Tolerance Factor (GTF). It enhances the tyrosine kinase activity of the insulin receptor and, which makes insulin more effective. Thereby controlling carbohydrate and lipid metabolism. Its deficiency is associated with high level of pro-inflammatory cytokines as Tumor necrosis factor alpha, Interleukin 6 and Creactive protein (TNF- $\alpha$, IL- 6 and CRP), high lipids levels and oxidative stress. However, Chromium supplementation cannot reverse diabetes if occurred, but it inhibits glycation process which is responsible for many of diabetes complications. ${ }^{6}$

Factors affecting chromium deficiency; include advanced age, diet rich in fat, milk and other high phosphorus foods tend to bind chromium to make chromium phosphates which are not absorbed through the intestines. ${ }^{7}$

\section{SELENIUM}

It is an essential trace element and is a key component of several selenoproteins required for normal health as Glutathione peroxidase. It plays an important role as an anti-oxidant, especially when combined with vitamin E. It is also essential for thyroid function and regulation of the immune system.

Selenium is generally well absorbed in the intestines; mostly in duodenum; some in the jejunum and ileum. Absorption is enhanced by the presence of other antioxidants, such as vitamins $\mathrm{E}$ and $\mathrm{C}$. After absorption, it is transported by Low Density Lipoproteins and Very Low Density Lipoproteins (LDL and VLDL), where it is stored in muscle, as well as in other organs, as the liver, kidney, and pancreas. ${ }^{8}$

It has been reported that serum selenium is significantly lower in obese patients. Its deficiency is associated with 
increased oxidative stress and impaired thyroid function; since type I iodothyronine 5'-deiodinase is a selenium containing enzyme. This enzyme is essential for production of active thyroid hormone tri-iodothyronine. However, the exact mechanism of its deficiency in obese patients is unclear; it may be due to decreased anti-oxidants. Also dietary antioxidants enhance selenium absorption. In addition, they are critical for maintaining and replenishing the overall antioxidant capacity of the body. ${ }^{9}$

Its deficiency is associated with increased risk of infection, atherosclerosis cardiomyopathy and myopathy, also thyroid fibrosis and irreversible hypothyroidism, if Se deficiency limits peroxide destruction by the protective action of Glutathione peroxidase. ${ }^{8}$

In conclusion; the bioavailability of trace elements may be disturbed in obese patients, and the exact prevalence of this alteration is still unknown. Deficiency of Serum Magnesium and Copper are inversely related to body weight and Body Mass Index (BMI). Disturbance of trace elements are associated with metabolic syndrome. ${ }^{6}$ Dietary supplementation is not the solution; also bariatric surgery may aggravate the deficiency in some conditions. Controlled weight reduction should be considered with extreme care.

\section{REFERENCES}

1. Günther T. The biochemical function of $\mathrm{Mg} 2+$ in insulin secretion, insulin signal transduction and insulin resistance. Magnes Res. 2010; 23: 5-18. doi: 10.1684/mrh.2009.0195

2. Means RT. Hepcidin and cytokines in anaemia. Hematology. 2004; 9: 357-362. doi: 10.1080/10245330400018540

3. Farasani G, Targhi F, Pishgahroudsari M, Mokhber S, Pazouki A. High prevalence of zinc deficiency in Iranian morbid obese patients undergoing bariatric surgery. J Minim Invasive surg Sci. 2015; 4(3): e33347. doi: 10.17795/minsurgery-33347

4. Kazi T, Afridi I, Kazi N, et al. Copper, chromium, manganese, iron, nickel, and zinc levels in biological samples of diabetes mellitus patients. Biol Trace Elem Res. 2008; 122(1): 1-18. doi: 10.1007/s12011-007-8062-y

5. Olusi S, Al-Awadhi A, Abiaka C, Abraham M, George S. Serum copper levels and not zinc are positively associated with serum leptin concentrations in the healthy adult population. Biological Trace Element Research. 2003; 91(2): 137-144. doi: 10.1385/BTER:91:2:137

6. Song H, Kim K. Associations of serum minerals with body mass index in adult women. European Journal of Clinical Nutrition. 2007; 61: 682-685. doi: 10.1038/sj.ejcn.1602568

7. Hepburn DD, Vincent JB. Tissue and subcellular distribu- tion of chromium picolinate with time after entering the bloodstream. J Inorg Biochem. 2003; 94: 86-93. doi: 10.1016/S01620134(02)00623-2

8. Rayman MP. Selenium and human health. Lancet. 2012; 379(9822): 1256-1268. doi: 10.1016/S0140-6736(11)61452-9

9. Hawkes WC, Keim NL. Dietary selenium intake modulates thyroid hormone and energy metabolism in men. J Nutr. 2003; 133(11): 3443-3448. 